\title{
The Front Seat Passenger: How to Transfer Qualitative Findings into Design
}

\author{
Sebastian Osswald, ${ }^{1}$ Petra Sundström, ${ }^{1,2}$ and Manfred Tscheligi ${ }^{1}$ \\ ${ }^{1}$ CD Laboratory, ICT\&S Center, University of Salzburg, 5020 Salzburg, Austria \\ ${ }^{2}$ Mobile Life Centre, 16429 Kista, Sweden \\ Correspondence should be addressed to Sebastian Osswald; sebastian.osswald@gmail.com
}

Received 15 October 2012; Revised 4 February 2013; Accepted 26 May 2013

Academic Editor: Paul A. Green

Copyright (c) 2013 Sebastian Osswald et al. This is an open access article distributed under the Creative Commons Attribution License, which permits unrestricted use, distribution, and reproduction in any medium, provided the original work is properly cited.

While the field of automotive HCI research abounds in driver-focused design and studies of driver distraction, relatively little attention has been directed to the front seat passengers. A challenge for designers and researchers is the ideation through exploration of passenger experiences and needs and the question of how to integrate them in design solutions. In this paper, we ground an ideation exercise based on results of a probing study conducted at two petrol stations. A probing package for front seat passengers was designed and distributed in cooperation with a petrol station company. Approximately 700 customers were approached randomly and 90 probe packages were handed out. 30 probing packages were returned and a segment clustering and a qualitative analysis were performed. The results gave insights into the activities and needs of front seat passengers and were then used in a design workshop together with a group of industrial designers. A set of ideas for novel interface solutions for front seat passengers were developed such as the invisible engine (look through the motor block with a display-based camera system). We further discuss the challenges and shortcomings of how to interpret and express ideas when transferring qualitative research findings into design.

\section{Introduction}

A great deal of time is spent driving-for business (to go to work and to appointments), for leisure (to visit family, friends, or a vacation destination), and for other purposes. The number of people within the vehicle changes, depending on the purpose for the trip. The driver may be alone or accompanied by passengers. For the front seat passenger, travel time can be a time to relax, spend family time together with those in the vehicle, or to complete tasks such as using Facebook, making phone calls, browsing the web, or watching a movie. However, the front seat passengers seem to be slightly forgotten in the field of automotive research. In most studies, the role of the front seat passenger is related to the task of driving the car, for example, assisting the driver with navigation (as in, e.g., [1]).

Every researcher and developer acknowledges that driving safely is crucial and designs and implements technology accordingly. Scientific research focuses on how to measure distraction in order to increase safety and on how to avoid situations that might affect safety (e.g., $[2,3])$. The front seat passenger is most often regarded as additional support to the driver and the driving situation. However, drivers primarily travel in familiar areas (as reported in [4]) and drivers tend to use navigation systems when going to familiar destinations as reported by Lo and colleagues [5]. Thus, there are moments and situations when it is possible for the front seat passenger to pursue his/her own tasks. The questions here are as follows: What are the desires and needs of the passenger? How can we design for those desires and needs?

A more detailed analysis of how the social situation and the interaction in the car look like is desirable [6] in order to understand the relationship between driver and passengers and how the needs of front seat passengers differ from existing knowledge. Examining the car space itself should not mean to only focus on what concerns the driver; it should also involve everyone who is present in a car. In the car space, the driver is not an isolated individual, which is why the driver and the driving task are strongly affected by the presence of passengers and the social relationship between 
them. Further, safety concerns appear as passengers might distract the driver or the front seat passenger may interfere in the driving task. According to McEvoy and colleagues, the likelihood of a crash is almost $60 \%$ higher in the presence of two or more passengers in comparison to driving alone; distraction through talking to passengers was one of the most common distracting activities (29.8\%) [7]. On the other hand, passengers could support the driving task with useful hints, for example, speed limits or through entering a destination in a navigation system. To make use of this potential, we are targeting the front seat passenger to explore and better understand the social space of the vehicle and derive inspiration for novel interface solution from passenger experiences.

In this paper, we present the procedure and results of a probing study that explores the desires and needs of front seat passengers. Cultural probing is a method used to inspire designers and engineers when designing interactive systems. The probing packages should support the participants to document and record specific feelings and experiences that can be used to stimulate imagination for novel interface solutions [8]. The probing packages were given to participants and included artefacts that serve as inspiration for the participants to gather data about their experiences and thoughts.

To draw inspiration from the results of the probing study, we presented the materials to a group of industrial designers. As stimulation and guidance to those interested in this design space, we provide descriptions of the most exciting and promising ideas we have collected. Within this paper, we discuss the issues and difficulties of presenting qualitative data to designers. There are two foci: (1) the step-by-step procedure of gaining inspiration for design ideas and (2) how to apply this procedure in a way that it tackles the challenges of transferring qualitative research findings into design.

We present the related work in the Section 2, followed by Section 3 which reports the topic of front seat passenger and application of cultural probing in the vehicle context. Within Section 3, probing materials, participants, procedure, and the results and data analysis are described. A detailed description of our design workshop is provided in Section 4, including the results according to a categorization provided by the participating researchers after the workshop. Section 5 contains the conclusion of transferring qualitative findings into design and the summary.

\section{Related Work}

Since Norman wrote his article saying how "there's an automobile in HCI's future" [9] in 2003, automotive research has vastly progressed in various areas. Norman feared "that all the errors of the past, errors in nuclear-power control rooms, in process control rooms, in the control of ships, and commercial aviation will simply get repeated" [9]. He was apprehensive that he or his colleagues would not be consulted when the engineering decisions in the field of automation are to be made. What we can see is that automotive research results find their way more and more into the automotive development process, for example, the rising interest from industry in conferences such as AutomotiveUI (Automotive User Interfaces and Interactive Vehicular Applications Conference (http://www.auto-ui.org/)). Nevertheless, we share the legitimate concern regarding fear that errors from the past will be repeated and argue for addressing the needs of every passenger in the design space of a vehicle to avoid distraction in the first place.

The importance of the car as a design space (e.g., [10-12]) has already been identified, but automotive HCI research has mainly been focusing on the driver, while often neglecting the other passengers in the car. A broader perspective of the social situation in the car was taken by Juhlin [13] in the field of automotive research. From an ethnographic approach on the social experiences of driving and travelling by car, they designed the Sound Pryer application [14] which is a "collaborative" MP3 player where the users (driver and/or passengers) can play their own music but also hear what other cars nearby are listening to. Brunnberg and Juhlin have also designed a backseat gaming platform [15] in which the world around the car is turned into a fantasyland filled with virtual creatures, treasures, and adventures. By pointing a gaming device towards objects they pass, the playing children can defend themselves against attacking creatures, pick up magic artefacts, or collaborate with players in traffic. Further challenges of ethnographical studies were discussed in the workshop "We are not there yet: enhancing the routine drives experience in the car context" [16] at the 2012 AutomotiveUI conference, focusing on statistical information about driving patterns and automotive technology trends "in order to make the boring and mundane attractive, entertaining, and engaging." Gridling and colleagues [17] furthermore conducted an ethnographic study in the car context itself, examining the collaboration between passengers and drivers. During various car trips, a researcher documented collaborative support, remarkable driving situations, and additional information that aimed to inform future in-car assistance. Other work conducted from a broader perspective on driving is the probing study by Wilfinger and colleagues [18], in which probing materials were given to children travelling in the backseat of cars. A result of this study was the RiddleRide game, in which questions about objects in the surroundings are posed at varying levels of difficulty to the people travelling together.

A challenge remains in that transfer of findings from ethnographic or qualitative research, such as a probing study, into design. The question is how to collect, formulate, and present the results of a qualitative study and transfer those results into a design process that inspires and guides design.

\footnotetext{
"In that process, the message (e.g., the qualitative user study results) is often skewed when passed on from one phase to another. Moreover, the way insights are communicated is often not inspiring enough. There is a lack of appropriate strategies and tools for how to communicate study results between different phases and between different stakeholders, so that informed design decisions can be made and data can be successfully used as
} 


\section{inspiration for design tasks throughout the whole design process." [19]}

Therefore, this paper is not simply about a probing study we have performed, but also a solution of how we have presented the results of this study to a group of industrial designers to get inspiring new solution for interfaces for the front seat passenger. We decided to follow this procedure to find ways to transfer what we learn from users' practices into design, as this is something that is not easily done. In fact, this is one of the major "wicked" [20] problems of interaction design, the problem of transferring or translating qualitative user study findings into something that can be used in design. For supportive tools, we thus need richer descriptions of work that can act as case studies in this direction. The presented study and the transfer process document how self-reported findings can be used in design for future vehicle interfaces, the results that were obtained from the designing sessions, and the problems that were encountered in achieving these results.

\section{Understanding Front Seat Passengers: The Probing Study}

To open up the design space and to gather information on how front seat passengers would benefit from an IVIS, we handed out probing packages inspired by Gaver's cultural probes [8] to randomly selected front seat passengers approached at two locations in Salzburg, Austriain August 2011. The material was designed for application on longer car trips. The study duration was one month to ensure that the participants were together on at least one longer trip during this period. Longer car trips were well suited for probing materials that suggest, for example, drawing a novel interface, as a longer period of travel would be needed to complete the task. It was also possible to finish a longer task over the course of several short trips or to use a short trip to fulfill a quick task, such as noting impressions of a certain driving situation or describing specific experiences.

As opposed to diary studies, cultural probes provide a more intense way of gathering information and material about people and their thoughts and activities. Unlike traditional methods (e.g., usability testing, observation, and field studies), the technique separates the researcher from the process of gathering information and allows the participants to self-report. In user studies, the presence of the researchers often influences the behaviour and decision-making process, as the participants feel observed and remain in a socially controlled environment. Different results may occur if participants would be alone. Instructing the participants to report and reflect on situations that are particularly chosen and framed by a proper research agenda can help to decrease the negative influence emanating from the presence of researchers. This becomes especially important regarding the context in which a study is conducted. An automotive vehicle is a limited physical space for approximately five people. Placing a researcher in this context is to penetrate a private space, where most often only friends, colleagues, and relatives of a participant have access. It, therefore, seems valuable to give participants the opportunity to report by themselves about their experiences while driving, in order not to disturb the driver-passenger relationship and to gain further authentic results. Cultural probing as a qualitative method addresses these issue and provides a procedure for researchers to design materials that target at supporting the front seat passenger to report about certain driving situations.

The gathered results from cultural probes are particularly useful early in the design process to gain ideas and be inspired and for a further ideation phase. During the process, randomly selected participants are approached and invited, given a kit of materials, and briefed about the requirement to record or note specific events, feelings, experiences, or interactions over a set period. At the end of the in advance specified period, the materials are collected and analysed. In recent probing studies, the method of adding interviews in advance was introduced in order to supplement, validate, and explore the information gathered by the participants. The information gathered is then analysed and documented by the researchers.

3.1. Designing the Probing Materials. Originally, Gaver's probes [8] consisted of a diary, index cards, maps, a photo album/a media diary, and a disposable camera. Due to the safety-critical car context, we decided to alter the probes to be more suitable for front seat use. We reviewed the original probes materials according to their properties (what they are made of and how can they be used) and excluded the disposal camera, as we feared that the flash could distract or blind the driver. We tested a camera without flash in the car during different light conditions, but the results were not satisfying as the inside of the car was overall too dark. The geographic maps were replaced by a creative booklet, since the maps were used context dependently in the original probing package and not applicable to our study. Our booklet contained a set of context-related tasks and questions that aimed to make the front seat passengers reflect on their experiences and their role in the car. We wanted the passengers to stay within the context of a vehicle when working with the probes, in order to maintain the experience of being a front seat passenger inside a vehicle. The probes should remain with the car to enable the front seat passenger to document experiences every time directly in the vehicle context. Collaboration with other present passengers was encouraged, including the driver when possible. The various probing tasks were also possible to perform when the car had stopped moving.

Each of the cultural probe packages included a booklet, a $105 \mathrm{~mm}$ by $148 \mathrm{~mm}$ sheet of white paper, an envelope, paperbased 3D glasses, and $3-35 \mathrm{~mm} \times 40 \mathrm{~mm}$ blank cards. In addition to the category-related sheets, the booklet contained a postcard and a treemap.

Using the provided tasks, we wanted the participants to think about their role as the front seat passenger, what they do while being the passenger, and how they behave while travelling by car. Passengers were encouraged to think about what is missing and what experiences they would like to have in the passenger seat. In total, ten inspirational situations were designed, divided into five categories: good versus bad front seat passenger cockpit, information desire, information 
sharing, visions for a front seat passenger cockpit, and front seat passenger needs.

For the category good versus bad front seat passenger cockpit, the participants were asked to judge the front seat passenger area and to describe the positive and negative aspects. The second inspirational idea was to write a short speech, accepting the Design Oscar for the best design of a front seat passenger device.

For the information desire category, we included paperbased 3D glasses with red/green glasses for the passengers, to put on and imagine the car being a 3D theater. We wanted to know what kind of augmented 3D events they could imagine in and outside the car. We then asked participants to write down what information they would like to have in a set of given situations (e.g., when it is raining or when backseat passengers are troublesome) in order to broaden our perspective on what information passengers may desire within the car.

Information sharing is an upcoming topic in the automotive domain [21] and was provocatively addressed by asking the passengers to write down travel related items they never would tell the driver on three little cards. A sealable envelope was added for the passengers to put their secrets inside. To encourage participants to think about a potential design, they were also asked to think about what applications (e.g., $\mathrm{TV}$, games, or email) would be suitable for the driver, the passenger(s), and/or both.

Passengers were to be creative for the theme visions for a front seat passenger cockpit. We asked them to draw an IVIS and place it where they would like it to be within the car (e.g., in the car ceiling, on the door, or on the console). Passengers were also asked to use their imagination and draw futuristic technologies they would like to use in the front seat passenger area.

In the last theme, the front seat passenger needs were written on postcards so that the participants could imagine sending to a friend to complain about items they felt were missing regarding their regular activity as a front seat passenger. Table 1 gives an overview about all categories and materials used.

The strategy we took in designing our probes (see Figure 1) uses a provocative approach in which tactics of personal involvement are used to strip away participants' objections and open up for new perspectives [22].

3.2. The Participants. As the probes method is used for a subjective view beyond what is graspable with methods like ethnography, we wanted to keep participants within the personal context of the car and chose not to bring them into the lab for a formal introduction seminar. We searched for an approach to recruit potential participants in context. Among several possibilities, we choose petrol stations as our recruiting area [23]. Petrol stations have a high frequency of visitors (possible participants) and passengers would have time, during the fuelling process, to speak with researchers. We were inspired by Kern and Schmidt's survey study that was conducted at a petrol station [24]. Due to the high frequency of potential participants arriving at the petrol

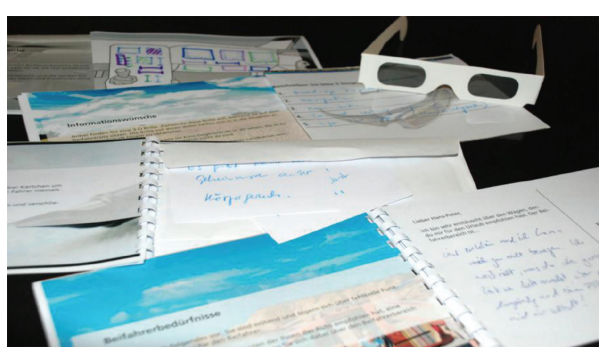

FIGURE 1: The probes: creative, descriptive materials.

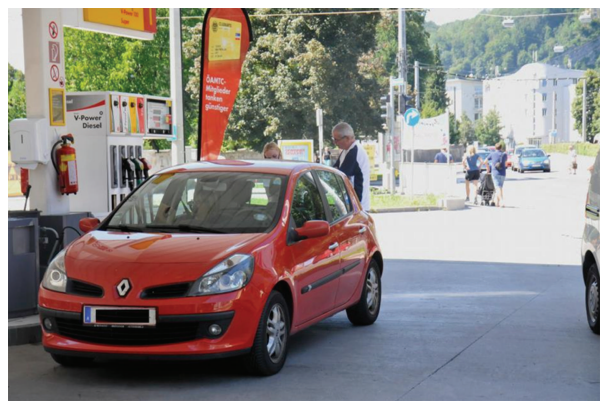

FIGURE 2: A researcher distributing probing packages at a petrol station.

station, we were not able to keep track of the exact number of passengers approached. Participants were selected randomly and approached regardless of gender or car type. To choose whom to approach of the many customers, quick decisions were made based on the license plate and whether a car was full with traveling accessories to distinguish between local customers and those simply passing through. Those with local license plates or from nearby cities were chosen to increase the chance of the participant's ability to return the probes to the petrol station. Participants were asked to return the probing materials to the petrol station where the materials were handed out. As Salzburg is close to the boarder of Germany, this included cities from Germany as there are a large number of people who drive to Austria to fuel their cars.

Having the participants return their probing package to the petrol station enabled them to independently return the materials and take their time to complete them and further does not require additional actions for shipping them. The collection of the materials was prearranged with the station staff. We expected a higher returning rate than in usual probing studies, as the packages could conveniently be returned upon the next visit to the petrol station. In retrieving and returning the packages at the petrol station, passengers were able to stay in vehicle context from the beginning to the end of the study. Figure 2 shows a researcher explaining the probing study to a petrol station customer.

3.3. The Procedure. Drivers were often present when describing the goals and aim of the study to passengers. We used this opportunity to ask the driver to return the probes to the petrol station within a month's time, whereupon the driver would receive a voucher for a premium car wash as an incentive. 
TABLE 1: Overview about the probing materials.

\begin{tabular}{|c|c|c|}
\hline Category & Focus & Material \\
\hline Introduction & $\begin{array}{l}\text { A summary of the introduction to the study } \\
\text { given by the researcher, providing } \\
\text { information about the study procedure }\end{array}$ & 2 pages in the booklet \\
\hline $\begin{array}{l}\text { Good versus bad front seat } \\
\text { passenger cockpit }\end{array}$ & $\begin{array}{l}\text { To write a 5-sentence assessment of the } \\
\text { negative/positive aspects of the interior } \\
\text { design of the front seat passenger area }\end{array}$ & 4 pages in the booklet \\
\hline Information desire & $\begin{array}{l}\text { Documentation of informational needs that } \\
\text { appear during a trip, determining the } \\
\text { potential of augmented reality in the car }\end{array}$ & $\begin{array}{l}4 \text { pages in the booklet, for example, } \\
\text { categories, 3D glasses }\end{array}$ \\
\hline Information sharing & $\begin{array}{l}\text { Determining which information is useful for } \\
\text { the front seat passenger and which } \\
\text { information should not be shared with the } \\
\text { driver, using cards to note down details } \\
\text { concerning the driver }\end{array}$ & $\begin{array}{l}6 \text { pages in the booklet, Tree } \\
\text { diagram, paper, pencil, envelop, } \\
\text { three cards }\end{array}$ \\
\hline $\begin{array}{l}\text { Visions for a front seat passenger } \\
\text { cockpit }\end{array}$ & $\begin{array}{l}\text { Sketch a computer especially for a front seat } \\
\text { passenger }\end{array}$ & $\begin{array}{l}2 \text { pages in the booklet, paper, pencil } \\
\text { and stickers, sketch of a vehicle } \\
\text { interior to complete }\end{array}$ \\
\hline Front seat passenger needs & $\begin{array}{l}\text { Documentation of activities during a car } \\
\text { ride, preparation of a post card to write } \\
\text { about a special car trip }\end{array}$ & $\begin{array}{l}4 \text { pages in the booklet, post card in } \\
\text { the booklet }\end{array}$ \\
\hline Information & $\begin{array}{l}\text { Informing the participant about the contact } \\
\text { person responsible for the study, providing } \\
\text { an address to return the package personally }\end{array}$ & 2 pages in the booklet \\
\hline
\end{tabular}

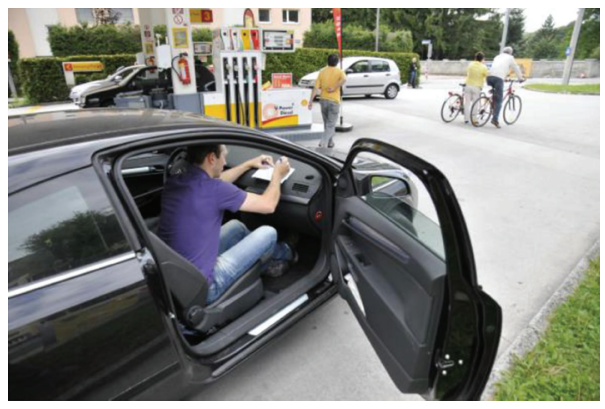

(a)

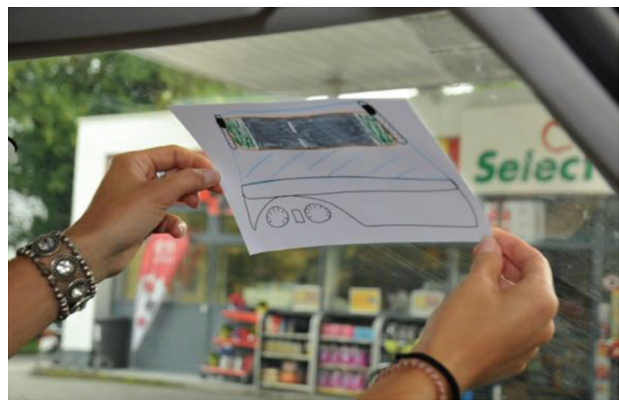

(b)

Figure 3: (a) A participant conducting the initial task of sketching a future user interfcae for front seat passenger (b) and showing where in the car it should be placed.

Drivers were asked to do this as it was more likely that the driver would motivate the passenger to complete the probing tasks, than it would be for the passenger to motivate the driver to drive back to the petrol station. The incentive for the front seat passenger was thus indirect, as the completion of the task was to do a favour to the driver.

To introduce our study and the probes procedure and initiate the start of the study, we asked participants to draw a sketch for a future IVIS (see Figure 3(a)) while waiting at the petrol station. When finished, participants were asked to place the sketch in the best position within a car for their IVIS. The participants explained their sketch to the researcher, who additionally took a picture of the desired position of the sketched IVIS (see Figure 3(b)). Figure 4 depicts three images from the participants, one of which represents the rear seat and their children to express the need of being aware of their actions. The participant pointed out that it is annoying to turn around all time to observe the children and that a camera interface was desired. The second sketch expressed the need for an convenient integrated workplace in the front seat passenger area. The third sketch aimed at expressing the need for certain information to be combined into one location. Once the sketches were collected, participants received the probing booklet and probes and were told the study should be conducted while being a front seat passenger.

On average, it took about fifteen minutes for the explanation of the study and for participants to draw their IVIS sketch. Our general experience was that the approached drivers and passengers were mostly willing to answer questions during this time. Passengers who took part seemed to be curious and interested in the topic. Nevertheless, some people refused straight away, claiming to be in a hurry. 

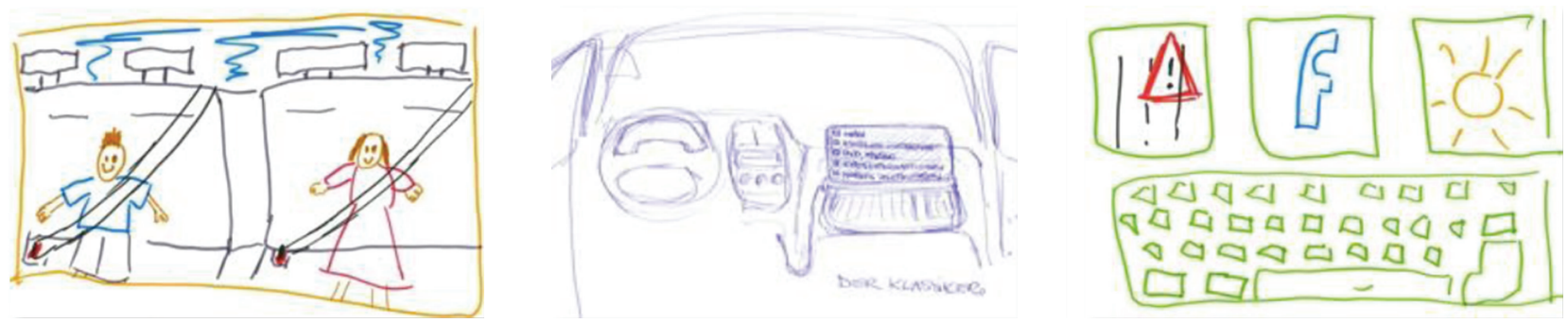

FIGURE 4: Three examples of sketches the passengers drew as the introductory task sketching for a future IVIS for the front seat passenger area.

3.4. The Results and Analysis. A total of 90 probing packages were distributed and 85 sketches were collected at the petrol station. (See Figure 4 for three examples of sketches.) Five sketches were missing as we allowed 10 participants who were in a hurry to complete the task later. Unfortunately, only five returned their IVIS sketches. After the preset period of one month, 30 probing packages were returned and collected from the petrol stations. All of these packages contained informational content and were usable for the qualitative analysis. As the probing was anonymous, no demographic data was collected during the study. We can only present the researchers subjective observation, where it can be said that the participants' age varied widely and that there was no tendency towards a single gender. It was noticed that two children participated and the rest of the participants appeared to be of legal age (older than 18 years).

Items that were left blank or contained notes about why a task was too difficult or considered not appropriate to complete were excluded. In total, 65 pages were left blank, whereby the drawing task from the category visions for a front seat passenger cockpit was left out most often. It is assumed that the initial drawing task at the petrol station affected the willingness of the participants to complete another drawing task. Looking through the rest of the materials, we received valuable feedback for every explored category. The category named information desire, in which the passengers were asked to use 3D glasses to imagine what additional things they could see in the car, received most responses. Every completed probing package contained this feedback. Ideas described included augmented overlays on buildings and landmarks presenting educational information about the surroundings, among others. Another wish was for more navigational information like a huge arrow that guides you through the traffic or a highlighting system for traffic signs, traffic lights, or safety-related events. The system would encircle, for example, the traffic signs with a glowing ring to make them appear more prominent. On the other hand, two participants mentioned that they would refuse any virtual overlay of information. The probes out of the category visions for a front seat passenger cockpit, in which the passengers had to sketch their future device, could also be described as successful. The system sketches showed the need for entertainment (TV/DVD/Movies), communication (social networking and video chat), or work support (email and organizer).

The 100 photos of the initial IVIS sketches placed in the vehicle were analysed in terms of placement. Figure 5 shows

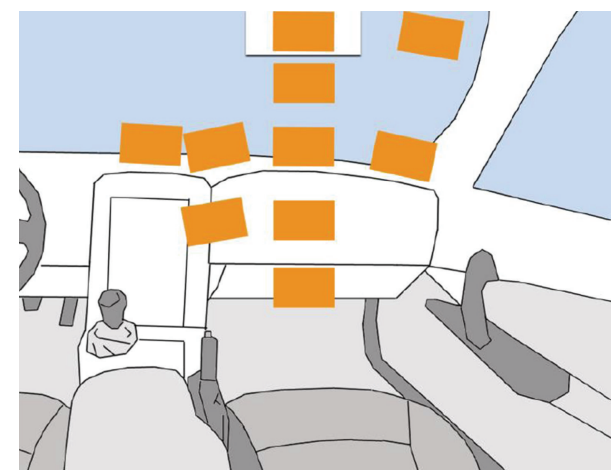

FIgURE 5: Overview about where participants placed the desgin sketches.

the distribution of the different positions mentioned. The most frequent placement was the central position of the glove compartment (35). The second most often position was on the visor (19). It is notable that the central right position in the windshield and the central right and lower right positions of the glove box were never chosen. Further, the driving mirror and the central console were not targeted, as they might be seen as areas intended solely for the driver.

Most participants admittedly commented on how they were bad at drawing. However, we received 85 individual sketches. Regarding these sketches, we experienced that asking for certain features and for how these features shall be placed and related to each other was a viable method in the limited physical space of the passenger area in the cars. While we expected more general answers to the categories front seat passenger needs, good versus bad front seat passenger cockpit, and information desire, we were surprised to receive significantly more specific and personal answers such as "I want information about if the next roadhouse provides wholefood" and "I need entertainment in the car and I need assistance to avoid the marital crisis every time I am driving with my husband. This is pure horror!"

In order to better understand the strong and differentiated views of what is important in the vehicle, we counted and categorized all single answers and drawings. Even though we are aware of how this is far from the original idea of the probes [8], we noted how the same item, feature, or experience repeatedly appeared and became intrigued about how this will affect the design of a future interface. This allowed 


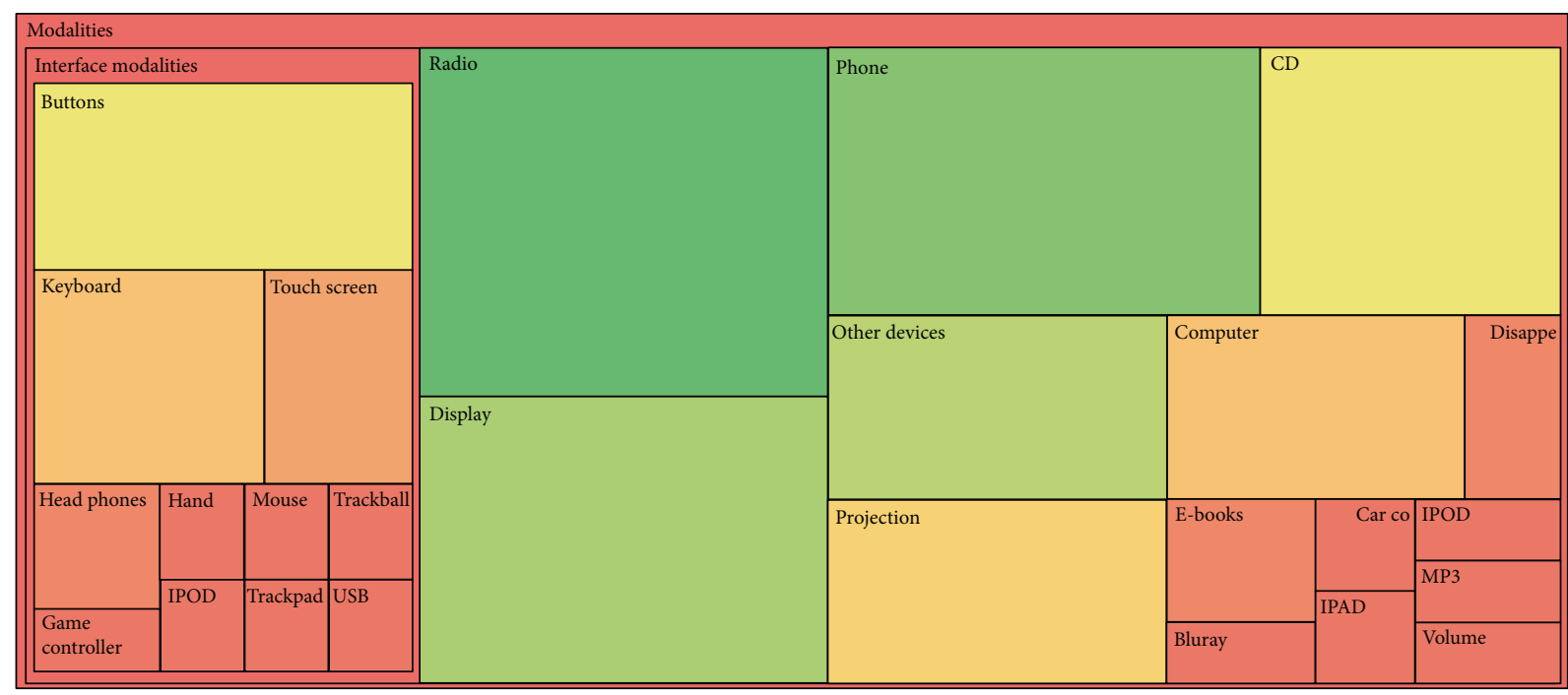

FIGURE 6: Segment clustering in NVIVO showing the distribution of the modality category; the size of each element correlates with how often an item was mentioned.

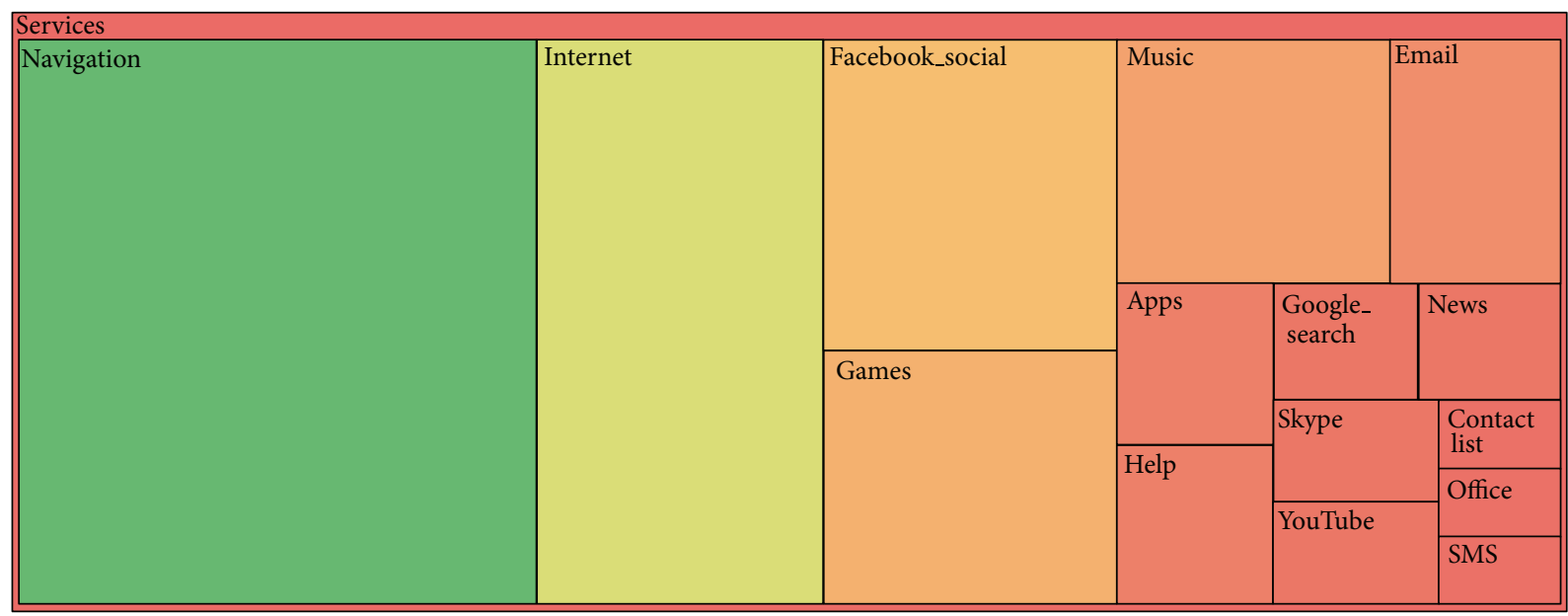

FigurE 7: Segment clustering of the service category.

us to become familiar with the probes and to identify the relationships between the materials. What will be presented later in this paper is how the analysis of the returned probing materials in fact turned out to be an additional tool for the designers in a way we had not expected.

Summarizing the petrol station study, two researchers approached approximately 700 customers over one week $(8 \mathrm{~h}$ a day) duration, distributed 90 packages, received 85 sketches, and took 100 pictures of the sketch placement. We received 30 packages with 235 filled out pages after a period of one month.

To ease the counting process and to build up more of an overall picture of the materials, we used the NVIVO software (http://www.qsrinternational.com/). This software allowed us to work with the unstructured materials and create cluster segments, referring to the occurrence and variety of the different requests that appeared in the materials. From the clustering, we determined four dominating categories of items requested: modalities, services, context, and information.
The different sizes of the squares and the different colors in the treemap represent how often each item was mentioned in relation to the other requests.

Figure 6 shows the clustered treemap for the category modalities. According to the transcription of the probing materials, radio, display, and phone were mentioned most often in the modalities category, whereas we also see larger tiles for a projection interface and buttons. For the category services, Figure 7 shows that navigation was the most frequently mentioned functionality. The items internet, social services, and games followed closely. In Figure 8, the category context is presented. The most often referred contextual information was weather, followed by time and speed. Areas were also considered in contextual reference, which is why windshield and the backseat are presented in this overview. The category information is presented in Figure 9. The TV was most frequently mentioned, followed by $\mathrm{DVD} /$ movie and information about the surroundings of the vehicle. Items 


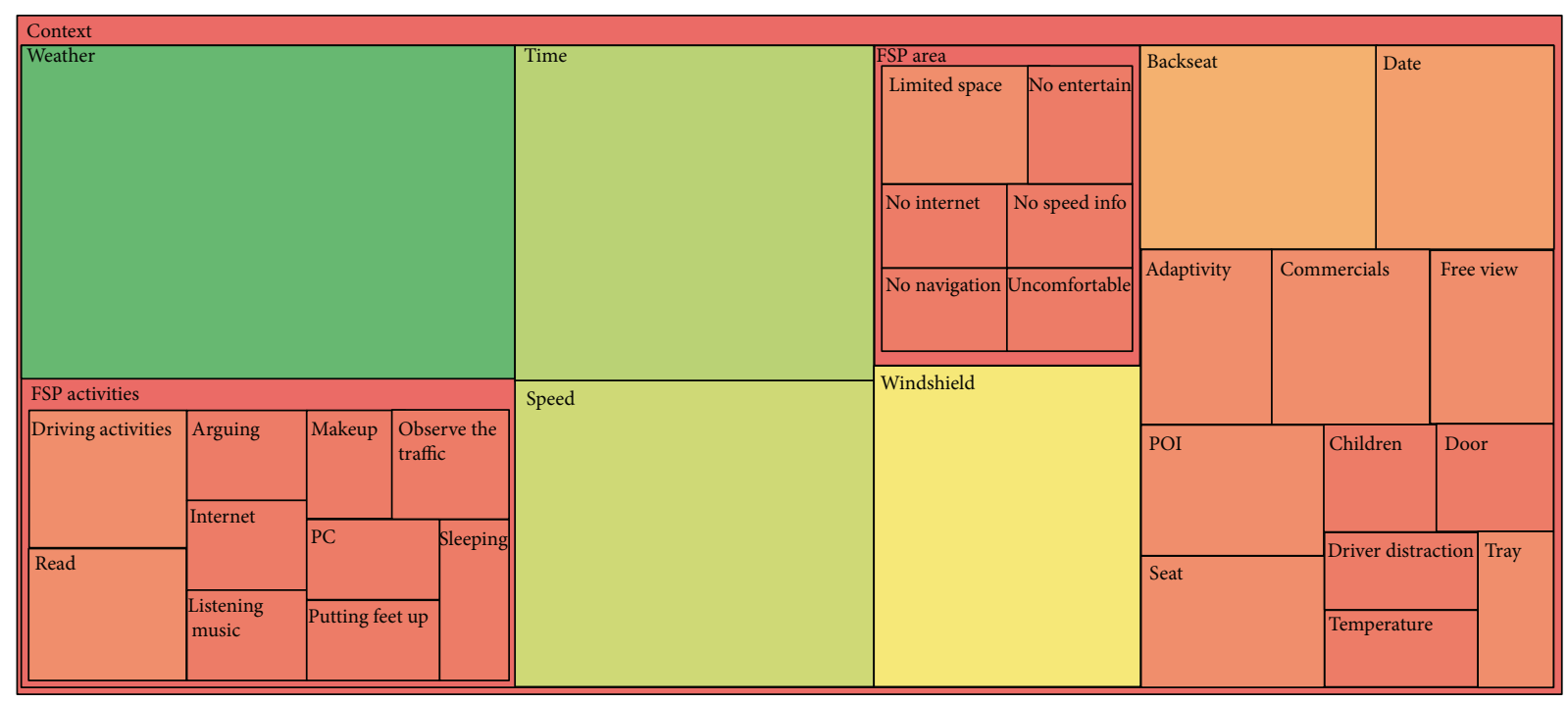

Figure 8: Segment clustering of the context category.

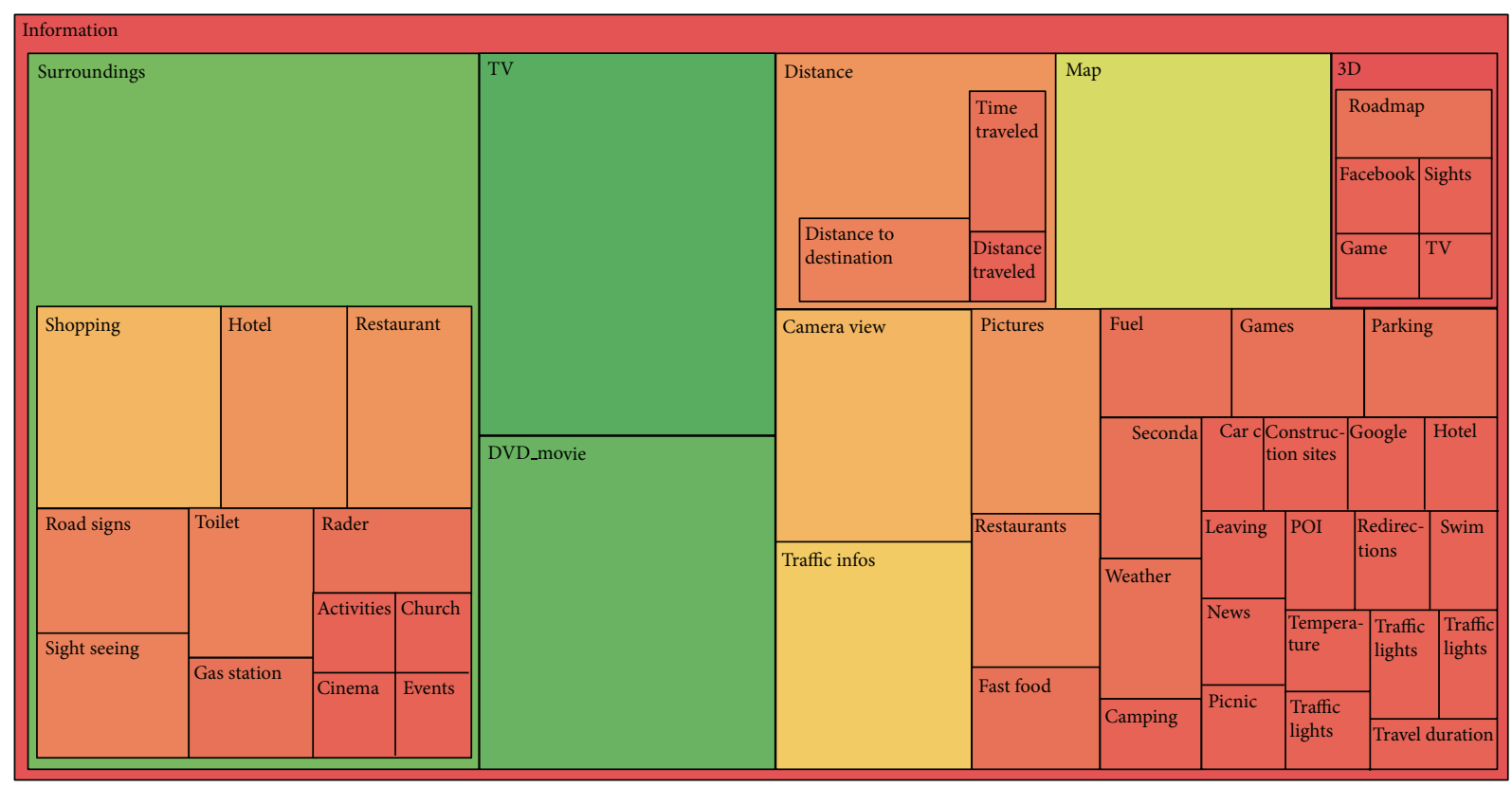

FIGURE 9: Segment clustering of the information category.

concerning a car trip like traffic, distance, or a map were also referred to.

This quantitative approach is uncommon when analysing cultural probing materials. The procedure of quantifying the data was similar to establishing an affinity diagram, a method commonly used within project management that allows large numbers of ideas stemming from brainstorming to be sorted in groups with focus on their relationships [25]. We used this approach to create an overview about what people think when they are engaged in discovering their personal space in the car. For us, it was useful to organize the content of the probing materials and to become immersed in the data. For the designers included later in the design process, the clusters highlight certain connection and idea categories. Summarizing the petrol station probing, the material revealed strong personal and emotional sequences that happen while driving (e.g., as the front seat passengers described their feelings about the driver in the envelop probe). During our analysis, the probes already inspired the participating researchers and discussions started about future automotive information systems.

\section{Ideation: The Design Workshop}

To investigate the value of the returned probes, we designed and organized a workshop where the whole material from 
the probing study was used as inspiration for a group of industrial designers in their sketching exercises for what could be a future IVIS for front seat passengers.

The five-hour workshop aimed to establish that generating valuable design ideas could be reached within an appropriate amount of time. To give the designers a chance of acquiring an understanding of the material in such little time, we used the segment clustering as a starting point to the material as we assumed that the clusters with its quantitative perspective would give the designers easier access to the materials.

4.1. The Participants. We invited five industrial designers from the University of Art and Design in Linz, Austria, to take part in this workshop. Two researchers (who were present in the probing study) participated in a workshop to introduce the topic and to support the designers. Industrial design, as a process, begins with the creation and development of a set of concepts and specifications that optimize the appearance, functions, and values for a system that aims to benefit the user and the manufacturer. Industrial designers are accustomed to developing concepts by considering the materiality of objects as well as the requirements of manufacturers and/or clients. This and the ability to place emphasis on aspects of a system that relates to characteristics of users' interests and needs grounded our decision to focus on industrial design before continuing into the processes of interaction design.

Each of the designers received an incentive of $€ 50$ for the time they spent in the workshop and for the work they completed during the session.

4.2. The Procedure. To build on the designers' skills to create ideas out of inspirational sources (in this case the probes in their original form in combination with the clustering), we decided to apply the nominal group technique (NGT) and combine it with a speeded sketching approach [26], as this method already showed its potential for designers to gain ideas. This procedure was chosen to allow for a session where the designers would get inspired and sketch a set of ideas in a brainstorming-like fashion. The ideation was thereby limited in time and to a set of certain tasks (four in total, referring to the clusters described in the results and analysis section of the probes information, modalities, services, and contextual information). The idea was that the restrictions would increase the attending designers' creativity [26].

The NGT was originally developed by Delbecq and Van de Ven [27]. This technique is a structured variation of a small-group discussion to reach consensus and encourage contribution from everyone involved. The process encourages both, individual thinking and group discussion, as it prevents the discussion or the work to be completed predominantly by a single person alone. In the original NGT process, a small group of five to six members (experts) are seated around a table and introduced to a topic. They are allowed to browse through supplied material to gather a holistic perspective. Thereafter, the researcher initiates an initial brainstorming session with an open-ended question in the area of interest. Each expert spends several minutes in silence individually
TABLE 2: Overview about the NGT inspired workshop procedure.

\begin{tabular}{|c|c|}
\hline Step & Task \\
\hline 1 & $\begin{array}{l}\text { A small group of } 5 \text { or } 6 \text { members (experts) are seated } \\
\text { around a table. }\end{array}$ \\
\hline 2 & $\begin{array}{l}\text { The collected probing materials are presented to the } \\
\text { group, it is allowed to browse through the whole } \\
\text { material. }\end{array}$ \\
\hline 3 & $\begin{array}{l}\text { An open-ended question is stated: In which way could } \\
\text { we redesign the car cockpits that it fit to the } \\
\text { imaginations of potential drivers? }\end{array}$ \\
\hline 4 & $\begin{array}{l}\text { Each expert spends several minutes in silence } \\
\text { individually brainstorming and notes down one idea. }\end{array}$ \\
\hline 5 & $\begin{array}{l}\text { Each expert sketches the noted idea and adds two } \\
\text { additional explaining sentences. }\end{array}$ \\
\hline 6 & $\begin{array}{l}\text { The ideas and sketches are presented to the group, no } \\
\text { criticism is allowed, but clarification in response to } \\
\text { questions is allowed. }\end{array}$ \\
\hline 7 & $\begin{array}{l}\text { All ideas are discussed after presentation to clarify } \\
\text { meanings, explain their logic and to state agreements or } \\
\text { disagreements. }\end{array}$ \\
\hline 8 & $\begin{array}{l}\text { The best ideas are selected and the votes are shared } \\
\text { within the group. }\end{array}$ \\
\hline 9 & A final discussion about the best idea is encouraged. \\
\hline
\end{tabular}

brainstorming, noting as many ideas as possible. Each idea is then introduced to the group, where no criticism is allowed, and only questions for clarification could be posed. Next, the ideas are discussed to clarify meanings, explain intended logic, and state agreements or disagreements. In the end, the ideas are prioritized using a multivoting or list reduction process. The overview about this process is documented in Table 2.

For our purposes, we separated the workshop into five main stages. First, a brief warm-up and introduction of the probes and the study is presented. Then, designers could familiarize themselves with the supplied materials (the booklets, the in-situ sketches, and the segment clustering). Similar to the NGT process, we then allowed for an individual brainstorming session, reflecting on the task and sketching ways to approach it. We followed this by having a presentation session to discuss and evaluate these ideas as a group. The last stage included a discussion on the procedure and materials of the task.

4.3. The Results: Ideas That Were Generated. In total, the designers generated 45 sketches. Of these sketches, we chose idea categories to summarize and classify the level of innovation of the ideas. The classification was done in an expert evaluation session with the goal to estimate the level of innovation for the ideas. Three HCI experts, with backgrounds in automotive user interface research, participated and rated the ideas according to the following three categories. First, state-of-the-art-level ideas represent approaches that could be included in available vehicles on the market. The second category, ideas with potential, summarizes ideas that were connected to available technology that may be realized in 


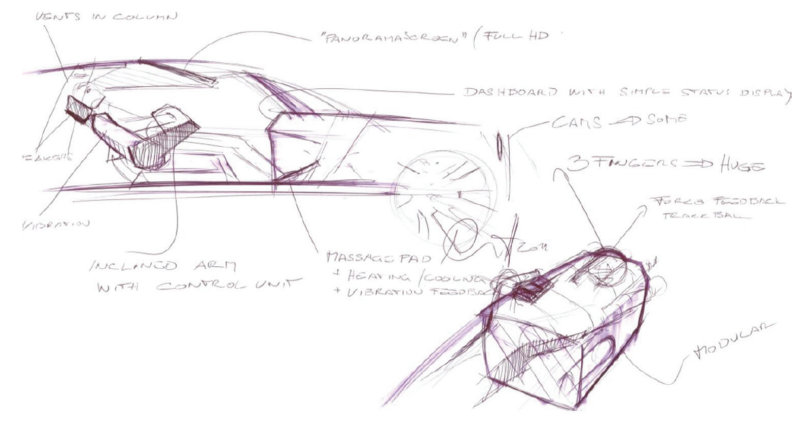

FIGURE 10: Armrest interface: thumb-controlled device and roof top interface.

the near future. A future outlook focused on ideas that explore novel approaches of experiencing the vehicle and stand out in terms of unique attributes. Each of these categories contains the original ideas designed in the sketching session in more detail, listed in ascending order from state-of-art level to more innovative solutions. All of the ideas were derived from the probing materials presented. We asked the designers to determine a certain material for each sketch, but we experienced that the majority of ideas were generated based on multiple impressions, making it difficult to assign a specific material to an idea. Nevertheless, some materials were described as more inspiring, which will be discussed in the following section. Safety aspects were also widely discussed, as the ideas violate laws, standards, and design guidelines, that need to be considered when developing information systems for the automotive market. We decided to neglect safety issues in this stage of ideation, as we felt this might reduce the attractiveness of the ideas and reduce the creativity of the designers. However, we do acknowledge that safety aspects need to be addressed if any of these ideas are further developed.

4.3.1. State-of-the-Art Level. Most of the sketches present the various modalities that were mentioned in the probing, such as touch interaction, buttons, and displays in an integrated form. We tried to divide the materials between the designers but almost all of them ended up designing for a modality centric perspective. A frequent suggestion was a basic control unit in the car, where the passenger could dock his/her mobile phone or smart phone and gain access to larger screens and more functionality in the car area. This would benefit from Internet access provided by the vehicle's communication platform and further allow storing vehicle-related settings on the personal phone device. One specific idea in this direction was a docking station in the door area that would offer directional touch interaction to enable the ability to easily browse through listed content coming from both the phone and from services stored in the car. This would be possible through an ergonomically designed thumb device positioned where the traditional armrest now is (see Figure 10).

Another idea was a concept of overlaying information in an IVIS, positioned in the central console, where it would display different content that would only be viewable from certain angles, allowing the passenger a private interaction space without disturbing the driver. The idea was to create a capsule within which the passenger gets the possibility to forget about the surroundings and relax. It was discussed how a separation might affect the social relation between a driver and a front seat passenger. The idea was, however, based on an even more social action described in our probes. Some front seat passengers described that they often try to sleep while they are on the front seat in situations when they want to recover from a previous driving period on a long distance drive. The capsule addresses this issue and tries to establish an environment for the front seat passenger to relax. In this direction, the designers also suggested various alternatives for private speakers and displays, for example, in the head rest or rooftop. This would allow the passenger and the driver to hear/see their own music/media in the car without disturbing each other.

Another designer had a well-being perspective and pointed out that the essential feature of the car is the "aesthetics of the surroundings." He sketched the front seat passenger area in a way in which the elements were to be nonintrusive through reductions of the elements' visibility. He reported that he deliberately included any feature he could think of (like a head-up display, a keyboard, and a touch screen), to envision a multipurpose cockpit for the front seat passenger (see Figure 11).

The window on the right hand side of the passenger was mentioned in connection with an interactive screen that would reserve a certain area for the driver to see the outside mirror on that side. This screen would enable the passenger to look out and see various augmented content in the passing environment.

Several of the designers' ideas addressed the question of how the entertainment desires of the passengers should be fulfilled. Various alternatives for using the windshield, for both $2 \mathrm{D}$ and $3 \mathrm{D}$ movies, were suggested. Issues related to driver distraction were heavily discussed and sketched in various ways (e.g., avoiding display reflections through altering the position or applying visual filters in head mounted devices to handle driver distraction caused by motion of projected objects in the windshield).

Having in mind that the designers started from scratch, these ideas provide an initial impression of the potential that this area has. The ideas in this section are very close to many state-of-the-art solutions, such as the overlaying information concept, which is very similar to the SPLITVIEW system from Daimler (http://www.daimler.com/). There are similar concepts and systems available on the market and in the literature that can be closely matched to ideas presented in this section.

4.3.2. Ideas with Potential. A rather simple but effective idea that was suggested in several ways was to remove the glove compartment and replace it with either a screen that could slide out of the console in front of the passenger or a table-like area for a keyboard and other modalities to navigate a docked phone device with. Similar to this slide out/in solution, 


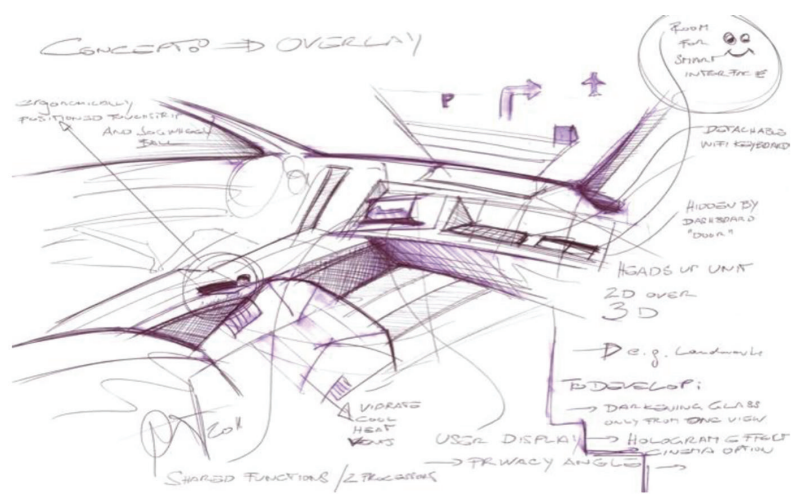

FIGURE 11: Aesthetic overlay concept with reduced element visibility.

a rail-based system was proposed that would use the most often idle space in the ceiling of cars. This solution would also serve for additional modalities and a screen that could be pulled down in front of the passenger. Figure 12 shows a moving display that was derived from an idea, inspired by the usage of the envelope probes themselves. This display can be bent towards the passenger, leading to a more private space that is not visible for the driver, like the cards in the envelopes.

The roof top interface idea (as sketched in Figure 10) appeared in other ideas also. The most frequently suggested idea for usage of this space was to install a ceiling screen that the passenger could see by tilting the seat back and making use of free space in the rear seat area if no passenger is sitting there. The concept was to pull the passenger out of the context of the car and provide a private space for watching films or for reading.

One of the more advanced ideas on the concept of a docking station for a personal phone device was the idea of letting the passenger send messages to be displayed on the outside of the car, like status updates in Facebook. One suggestion for this was to place an AMOLED (http://www.techopedia .com/definition/24217/active-matrix-oled) display (a display technology commonly used in mobile devices) in the area between the wing mirrors and the tail light following the upper edge of the doors to let a message run from the front to the back. We do not see these docking ideas as remarkable, due to existing connections between the car and a personal phone device. These ideas consider basic services like handling phone calls and so on; however, more advanced services in this direction are not that far off.

4.3.3. A Future Outlook. A few of the sketches were more futuristic and innovative. One such idea contained the gaming by foot idea. This gaming device can be slid into the passenger's footwell to allow for gaming through foot interaction while riding in the car. We especially like this idea, as it uses an available area in the car and also holds great potential for an in-car game (e.g., imitating the driving style of the driver or silently interacting with the passengers in the backseat for a group-based game). Further, we like this idea because it is an unusual interaction modality that would not disturb the driver if designed correctly. The gaming activities could take

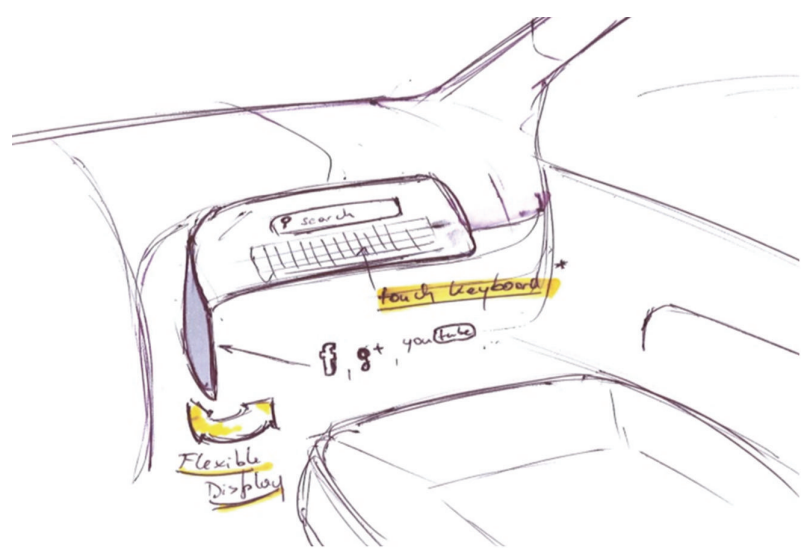

FIGURE 12: A flexible display, bendable for more privacy and without disturbing the driver.

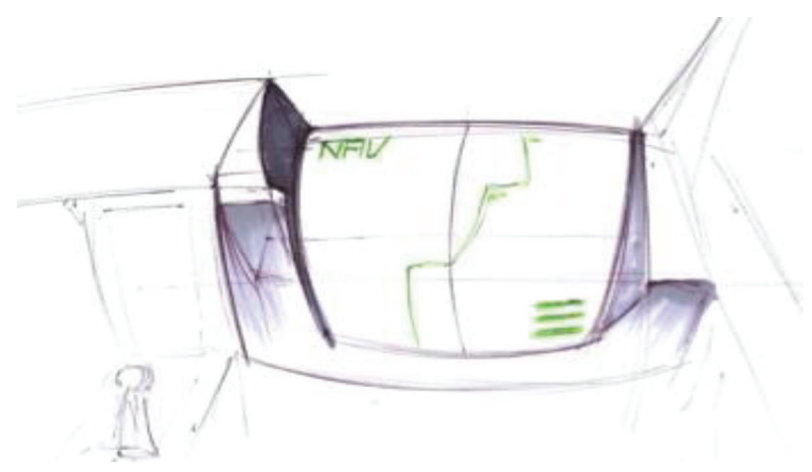

FIGURE 13: An integrated block interface physically separated from the console.

place in an augmented form for the inside and the outside of the car.

Another innovative idea is the invisible engine. This idea uses a block interface, as presented in Figure 13. This interface is situated in the area of the glove compartment, but it is innovative in the design of the front seat area. In this idea, it was suggested that the information would glow out of the dashboard. The surface of the interface should be similar to the dashboard and only the presented information should be visible in fine green, pulsating lines. The area could also be used as a window connected to a camera in the front of the car, allowing for the experience of seeing through the engine, looking out of a window right above the road.

To conclude this section, we want to address the fact that, to some extent, the ideas presented here are affected by how we wanted to find possible passengers' needs when not having to assist the driver. This focus directed us slightly away from other kinds of social interactions the passenger could have had with the driver that would not make him or her the codriver. Furthermore, our continuous research aimed to include interaction that could take place between the front seat passenger and the potential passengers in the back. However, foci have been directed almost exclusively towards the driver and the needs of the driver and potentially towards the issues of entertaining some children in 
the back [18]. We believe a more directed focus on the front seat passengers alone is needed as an initial step towards a safe but more holistic and engaging driving experience for everyone in the car. After all, not everyone is driving as a family of four and not every driver needs help or wants to continually interact while driving.

4.4. A Reflective Discussion on the Provided Materials. After the design exercise, we had a discussion with the designers regarding the task itself, the provided materials, and the topic of design, in general, and industrial design, specifically. This discussion was recorded by one of the present researchers to allow for documenting the arguments presented below.

When asked for the most inspiring materials, the designers liked the sealed envelopes with the secret items the passengers did not want to tell the driver. They stated their belief that the passengers knew these envelopes were to be opened and read. However, designers thought these envelopes allowed the passengers to more freely express their feelings. One designer enjoyed the impression that these notes revealed the true emotions of the passengers, such as "I do not like the smell of the driver" or "I'm really scared every time he is passing another car." He found these notes entertaining and used them to gain new inspiration when he was needing it.

"I really liked the envelopes, because to me they represent emotional verbal statements, and they tell me more than the other stuff as they express emotions." (Designer 1)

The designers expressed several times how they also liked the quantitative data. One of the designers explained how the quantitative data served as a validate tool to make sure that what he designed others would like too. Another designer said it was a way for him to see what the majority wanted. And when then asked if the unique and, perhaps, the more innovative requests excited him more, he stated how the car is a significantly more expensive device where individuality cannot be designed for in the same way as for less expensive items, for example, mobile phones. When further asked if these passengers requests could not be seen as additional equipment when purchasing a car, he answered:

"Yeah, but the additional stuff must not be added,
like you glue it on or something, it needs to be
integrated into the whole system." (Designer 4)

Another designer phrased it as follows:

"You know, you do not want to have the same ride as everybody else, but the advantage of having the same ride as everyone else is that it's cheaper, and if you want an individual ride it costs more." (Designer 3)

Further, the designers stated how they saw it as their task to take the requests of the users and break them down and combine the requests more into one integrated device. Referring to the various items and features that were asked for, one of the designers expressed it as follows:
"It is like this Swiss army knife coming out of the dashboard, but this represents how people think ... from those parts I can take most of my conclusions and put them together with the drawings and the emotions." (Designer 1)

Furthermore, the designers felt they had too little time for this task. However, they explained that in contrast to how they normally would need to spend a month's time to research on a topic, the provided materials were helpful in the same way in a much shorter time. They also stated that the topic itself also helped them since everyone is familiar with cars and they could empathize with being the front seat passenger, as well as the driver. They told us about a project where they were to design new ovens. This task had been harder for them as they were less familiar with ovens.

\section{Conclusions}

In this paper, we presented the results of a probing study conducted at two petrol stations. We aimed to explicitly identify the steps taken towards transferring the results of this study into the field of design. We focused on the front seat passenger instead of the driver, as we see potential in addressing the passengers' needs and experiences to improve travel experiences. Boehner and colleagues have already concluded that it appears in the literature, as if probe responses often lead directly to final system designs [19]. In the original probes work [8], there is an important intermediary step in interpretation called exploration and sketching. This is where the returned probes are interpreted and expressed through a series of ideas for different designs. As researchers and HCI experts without a deep background in conceptual design, we wanted to turn the results of our probing study over to a group of external designers. Transferring the quantitative data into design adds yet another important interpretational step to the multilayered process of expression and interpretation suggested by Gaver and colleagues [22]. Figure 14 shows a modified version of Gaver and colleagues' original procedure sketch, to which we have added this intermediary step of collecting and expressing qualitative user study results in a way that inspires design and design thinking.

In terms of the study procedure, the recruiting process in an area where the front seat passenger target group can be approached in-situ turned out to be successful compared with a previous conducted probing study [18] and further beyond the high number of creative materials that could be collected. Moreover, it proved to be successful to use a combined qualitative and quantitative approach in presenting the results to the group of experts - the industrial designers. Regarding the outcome of the workshop and the described ideas, it can be stated that this approach would be beneficial for anyone approaching a topic where the items worked with (i.e., cars) are slightly more expensive and when the requests of a majority have to be considered.

Some of the probing materials did not work as well as others (e.g., the sketches were returned in high numbers, but most of the passengers did not fill in the related pages of their own needs within the booklet). The workshop with 


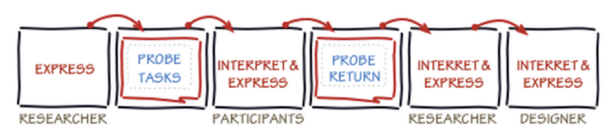

FIGURE 14: Our modified version of Gaver and colleagues' multilayered process of expressing and interpreting the probes [22].

the industrial designers could benefit from a longer timeframe (up to one month, depending on the targeted state of the ideas), to give more room for the designers' regular iterative procedures and perhaps to create more sophisticated ideas. From the perspective of the ideas themselves, they are to be considered as an initial step, although a valuable one, in the ideation phase and could serve as a starting point for anyone interested in the topic of designing for the needs and interests of front seat passengers. Our future work will address the challenge to iterate the probing method to be more suitable for the car context. We experienced drawbacks in some steps we took but managed to create valuable sources of inspirational material with our probing packages. A challenge in the future will be to develop probing packages that are standardized, to a certain degree, and adapted to the addressed target group, such as front seat passengers, drivers, or rear seat passengers. As described in the development process of our probes, the influence on safety due to the driving situation is a critical factor for probing studies that need to be considered regardless of the target group within the car.

\section{Acknowledgments}

The financial support by the Federal Ministry of Economy, Family and Youth and the National Foundation for Research, Technology and Development is gratefully acknowledged (Christian Doppler Laboratory Contextual Interfaces). The authors would like also to thank the Industrial Design Department of the University of Art and Design Linz.

\section{References}

[1] B. Brown and E. Laurier, "The normal natural troubles of driving with GPS," in Proceedings of the SIGCHI Conference on Human Factors in Computing Systems (CHI '12), pp. 1621-1630, ACM, May 2012.

[2] S. Osswald, A. Meschtscherjakov, D. Wilfinger, and M. Tscheligi, "Interacting with the steering wheel: potential reductions in driver distraction," in Proceedings of the International Joint Conference on Ambient Intelligence (AmI '11), pp. 11-20, Springer, November 2011.

[3] I.-M. Jonsson, C. Nass, J. Endo et al., "Don't blame me I am only the driver: impact of blame attribution on attitudes and attention to driving task," in Proceedings of the Extended Abstracts on Human Factors in Computing Systems (CHI EA'04), pp. 1219-1222, ACM, 2004.

[4] G. Leshed, T. Velden, O. Rieger, B. Kot, and P. Sengers, "Incar GPS navigation: engagement with and disengagement from the environment," in Proceedings of the SIGCHI Conference on Human Factors in Computing Systems (CHI '08), pp. 1675-1684, Florence, Italy, April 2008.
[5] V. E. Lo, P. A. Green, and A. Franzblau, "Where do people drive? Navigation system use by typical drivers and auto experts," Journal of Navigation, vol. 64, no. 2, pp. 357-373, 2011.

[6] A. Meschtscherjakov, D. Wilfinger, N. Gridling, K. Neureiter, and M. Tscheligi, "Capture the car! qualitative in-situ methods to grasp the automotive context," in Proceedings of the Automotive User Interfaces and Interactive Vehicular Applications (UI '11), pp. 105-112, ACM, 2011.

[7] S. P. McEvoy, M. R. Stevenson, and M. Woodward, "The prevalence of, and factors associated with, serious crashes involving a distracting activity," Accident Analysis \& Prevention, vol. 39, no. 3, pp. 475-482, 2007.

[8] B. Gaver, T. Dunne, and E. Pacenti, "Design: cultural probes," Interactions, vol. 6, no. 1, pp. 21-29, 1999.

[9] D. A. Norman, “There's an automobile in hci's future," Interactions, vol. 12, pp. 45-54, 2005.

[10] D. J. Wheatley, "Beyond the desktop: and into your vehicle," in Proceedings of the CHI Conference on Human Factors in Computing Systems (CHI EA '00), pp. 43-44, ACM, Hague, The Netherlands, 2000.

[11] A. Schmidt, A. K. Dey, A. L. Kun, and W. Spiessl, "Automotive user interfaces: human computer interaction in the car," in Proceedings of the 28th Annual CHI Conference on Human Factors in Computing Systems (CHI EA '10), pp. 3177-3180, ACM, April 2010.

[12] D. Kern and A. Schmidt, "Design space for driver-based automotive user interfaces," in Proceedings of the 1st International Conference on Automotive User Interfaces and Interactive Vehicular Applications (AutomotiveUI '09), pp. 3-10, ACM, 2009.

[13] O. Juhlin, "Social media on the road: mobile technologies and future traffic research," IEEE Multimedia, vol. 18, no. 1, pp. 8-10, 2011.

[14] M. Östergren and O. Juhlin, "Car drivers using sound pryerfield trials on shared music listening in traffic encounter," in Consuming Music Together: Social and Collaborative Aspect of Music Consumption Technologies, K. O'Hara and B. Brown, Eds., pp. 173-190, Springer, 2006.

[15] L. Brunnberg and O. Juhlin, "Movement and spatiality in a gaming Situation-boosting mobile computer games with the highway experience," in Proceedings of the IFIP Conference on Human-Computer Interaction (INTERACT '03), pp. 407-414, IOS Press, 2003.

[16] C. Montesinos, D. Szostak, and A. Zafiroglu, "We are not there yet: enhancing the routine drives experience," in Adjunct Proceedings of the 4th International Conference on Automotive User Interfaces and Interactive Vehicular Applications (UI '12), pp. 249-256, 2012.

[17] N. Gridling, A. Meschtscherjakov, and M. Tscheligi, “"I need help!" exploring collaboration in the car," in Proceedings of the ACM Conference on Computer-Supported Cooperative Work (CSCW'12), pp. 87-90, Seattle, Wash, USA, February 2012.

[18] D. Wilfinger, A. Meschtscherjakov, M. Murer, S. Osswald, and M. Tscheligi, "Are we there yet? A probing study to inform design for the rear seat of family cars," in Proceedings of the 13th IFIP TC13 Conference on Human-Computer Interaction (INTERACT '11), pp. 657-674, ACM, 2011.

[19] K. Boehner, J. Vertesi, P. Sengers, and P. Dourish, "How HCI interprets the probes," in Proceedings of the SIGCHI Conference on Human Factors in Computing Systems (CHI '07), pp. 10771086, ACM, San Jose, Calif, USA, May 2007.

[20] R. Buchanan, "Wicked problems in design thinking," Design Issues, vol. 8, no. 2, pp. 5-21, 1992. 
[21] O. Inbar and N. Tractinsky, "Make a trip an experience: sharing in-car information with passengers," in Proceedings of the 29th Annual CHI Conference on Human Factors in Computing Systems (CHI '11), pp. 1243-1248, ACM, May 2011.

[22] W. W. Gaver, A. Boucher, S. Pennington, and B. Walker, "Cultural probes and the value of uncertainty," Interactions, vol. 11, no. 5, pp. 53-56, 2004.

[23] S. Osswald and M. Tscheligi, "Gas station probing: the front seat passenger," in Proceedings of the Adjunct 3rd International Conference on Automotive User Interfaces and Vehicular Applications (UI '11), 2011.

[24] D. Kern and A. Schmidt, "Gas station flash survey-a method for interviewing drivers," in Proceedings of the Workshop on Automotive User Interfaces. Mensch und Computer, pp. 41-45, Bauhaus-Universität Weimar, 2007.

[25] H. Beyer and K. Holtzblatt, "Contextual design," Interactions, vol. 6, no. 1, pp. 32-42, 1999.

[26] J. Wentzel and S. Holmlid, "Speed sketching with designers: user inspired brainstorming," in Proceedings of the Designing Pleasurable Products and Interfaces, ACM, 2009.

[27] A. Delbecq and A. Van de Ven, "A group process model for problem identification and program planning," Journal of Applied Behavioral Science, vol. 7, no. 4, pp. 466-492, 1971. 

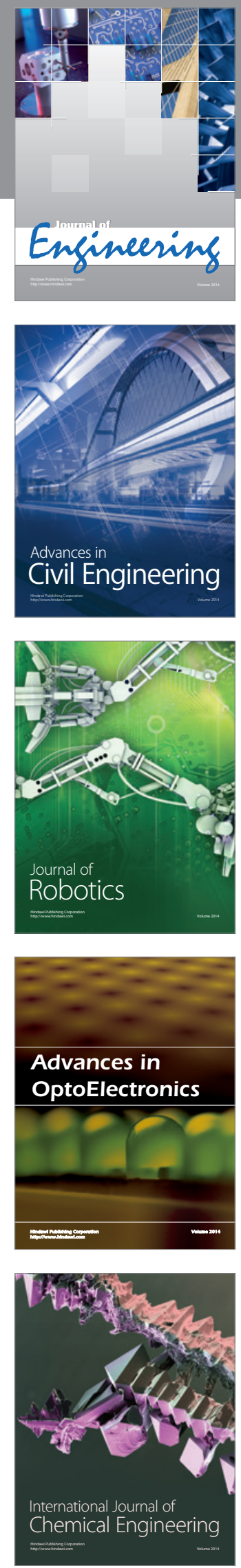

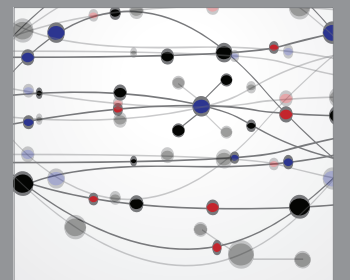

The Scientific World Journal
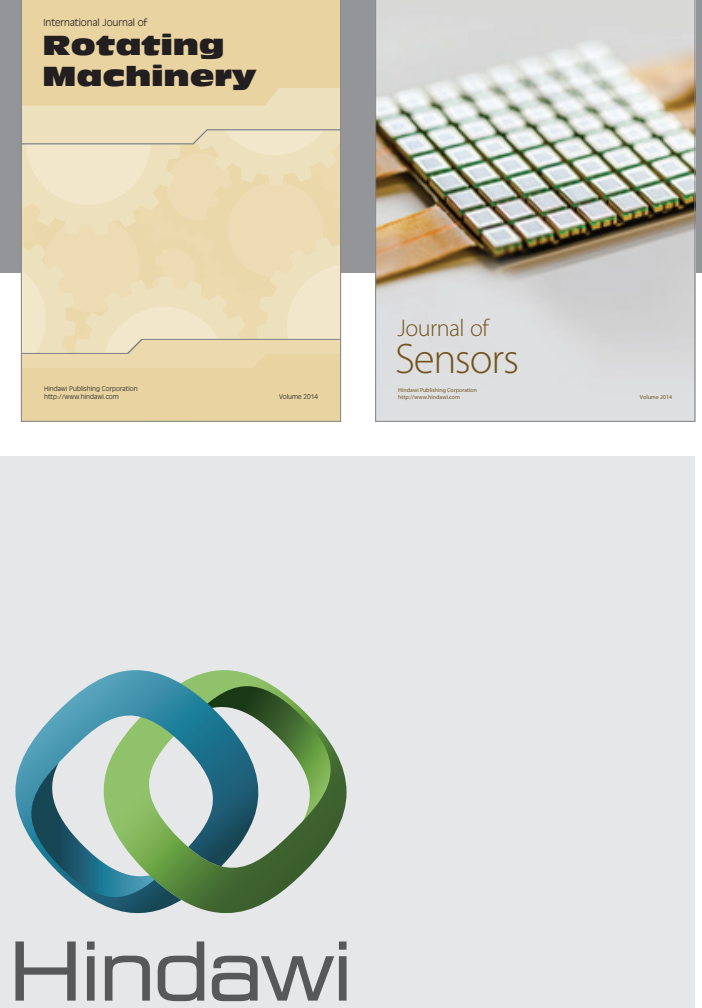

Submit your manuscripts at http://www.hindawi.com
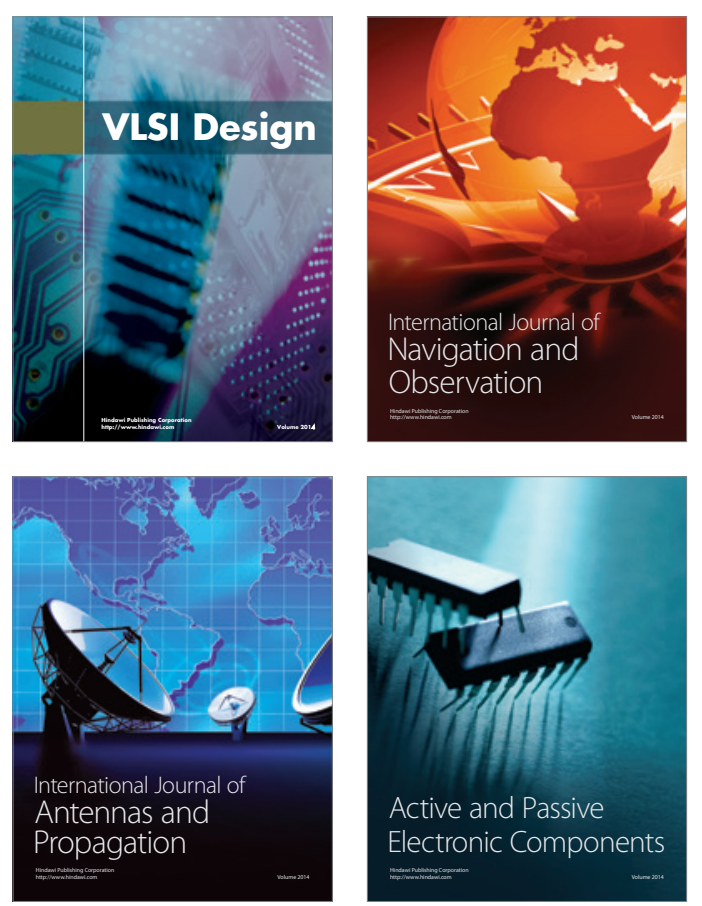
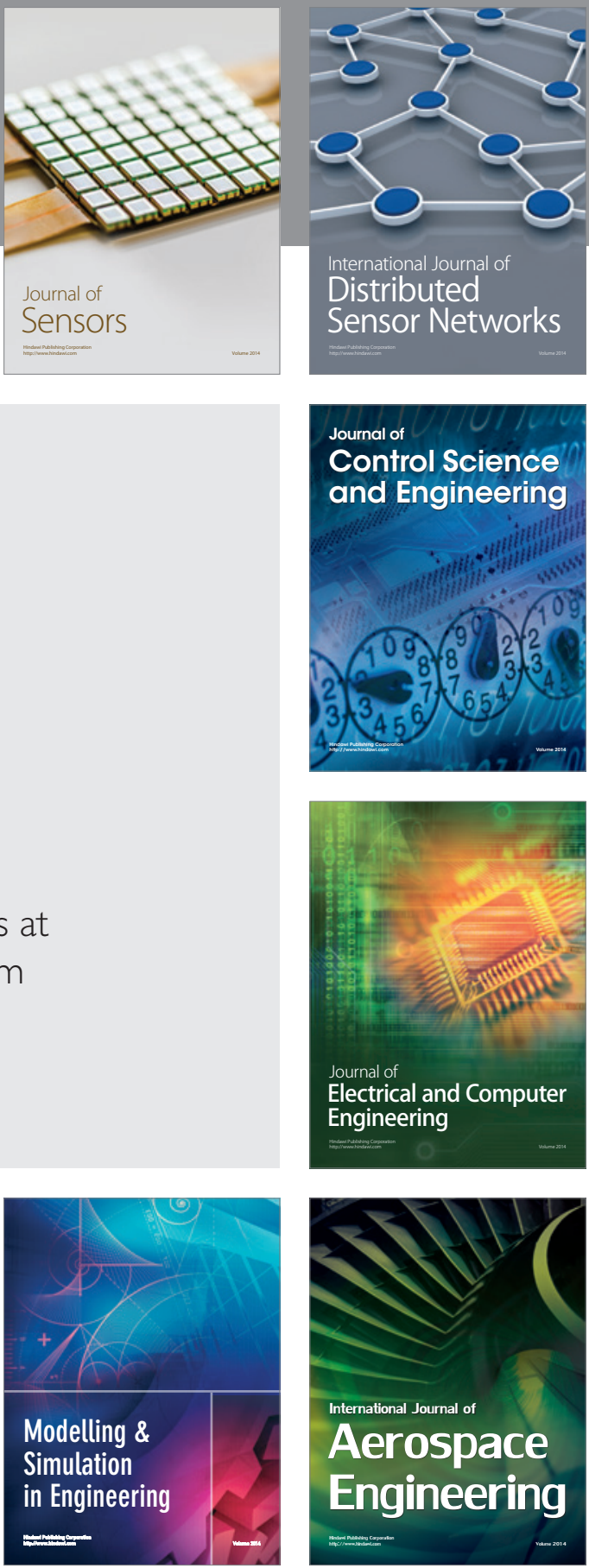

Journal of

Control Science

and Engineering
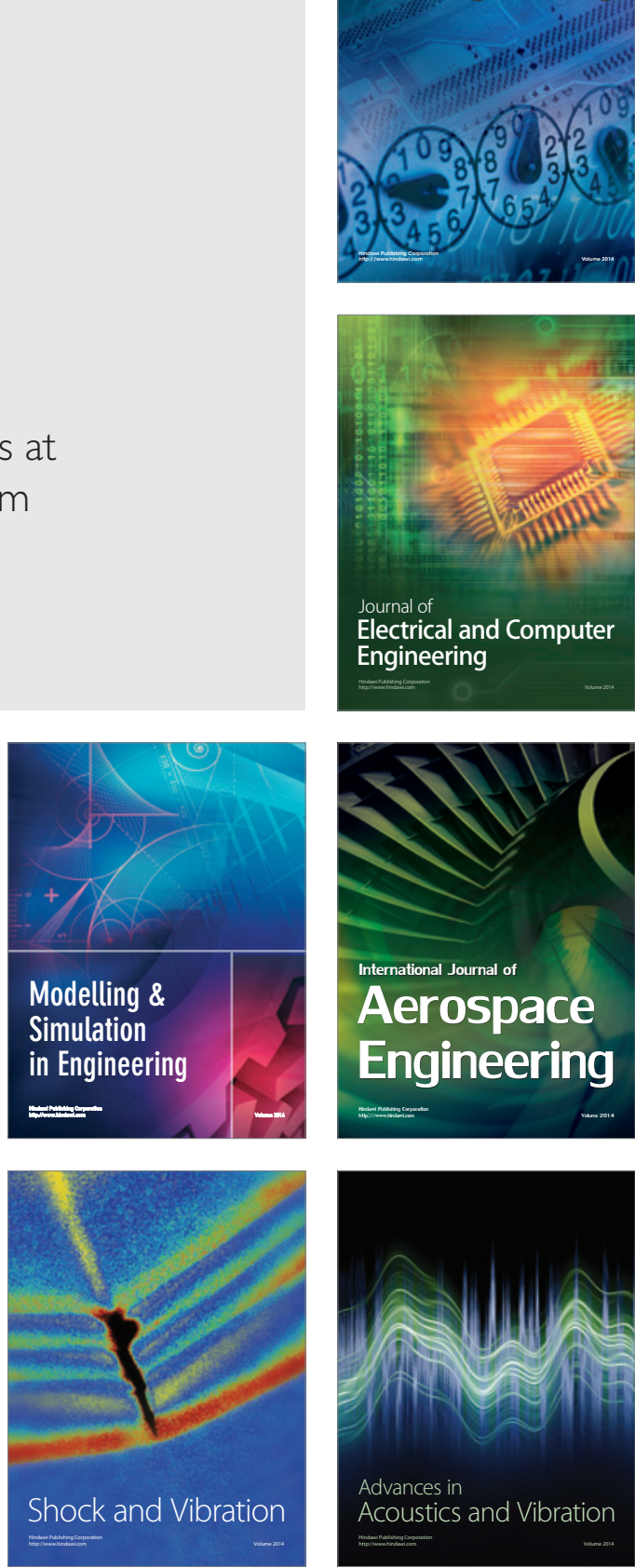